\title{
Effect of Intercritical Heat Treatment on the Microstructure and Mechanical Properties of Medium Mn Steels
}

\author{
Huseyin AYDIN, ${ }^{1) *}$ Elhachmi ESSADIQI, ${ }^{2)}$ In-Ho JUNG ${ }^{1)}$ and Stephen YUE ${ }^{1)}$ \\ 1) Department of Mining and Materials Engineering, McGill University, Montreal, OC, Canada. \\ 2) Internationale de Rabat, UIR, Aerospace Engineering School, Rabat, Technopolis Shore Bypass Rabat-Salé, Morocco.
}

(Received on March 20, 2013; accepted on May 28, 2013)

\begin{abstract}
In the present work, the effects of intercritical annealing parameters on the microstructure and cold rollability (deformation rate and ratio) of " $3^{\text {rd }}$ Generation Advanced High Strength Steels (AHSS)" were studied. Hence, this paper discusses the formation of microstructures with different volume fractions of ferrite, martensite, bainite and retained austenite (RA). Two novel microstructures have been created, based on two levels of manganese $(\mathrm{Mn})$ : (i) ferrite plus martensite nucleated in austenite microstructure (FMNA structures), using Mn levels of 5 to $7 \mathrm{wt} \%$ and (ii) ferrite plus retained austenite duplex structure (FADP steels) for a Mn level of $10 \mathrm{wt} \%$. In general, the ductility is a function of the amount of retained austenite and the strength is highly dependent on the martensite level.
\end{abstract}

KEY WORDS: Transformation Induced Plasticity (TRIP); Twinning Induced Plasticity (TWIP); Strain Induced Transformation (SIT); Stacking Fault Energy (SFE); Retained Austenite (RA).

\section{Introduction}

Over the last few decades, Advanced High Strength Steels (AHSS) have been very attractive to the automotive industry as a structural material for weight reduction and formability. These materials have a superior combination of strength and ductility, coupled with a relatively complex chemistry and microstructures. Nowadays, most of the AHSS possess a relatively high volume fraction of metastable austenite, which transforms under mechanical load. ${ }^{1)}$ In particular, rapid work hardening occurs due to strain induced martensite or twins formed from the metastable (i.e. retained) austenite, which also increases the work hardening of surrounding ferrite; this gives rise to high uniform elongation by delaying the onset of necking. A volume expansion due to this transformation also contributes to increased ductility. ${ }^{2,3)}$ Therefore, it has been claimed that high manganese steels with either twinning or strain induced martensitic transformation offer extraordinary mechanical properties, which leads to improved crash worthiness properties for better passenger safety. ${ }^{4,5}$

The extraordinary mechanical properties of high manganese (20-25 wt \%) steels are dependent on the composition and processing conditions, which are problematic. ${ }^{6,7)}$ High manganese content and oxidation behaviors of these materials are practical processing issues. Moreover, the competition with the lightweight materials makes it necessary to reduce the costs (i.e. amount) of alloying additions. ${ }^{8)}$ Hence, medium manganese ( 5 to $10 \mathrm{wt} \%$ ) steels are currently one

* Corresponding author: E-mail: huseyin.aydin@mail.mcgill.ca DOI: http://dx.doi.org/10.2355/isijinternational.53.1871 of the materials being developed to harness the promise of $2^{\text {nd }}$ generation steels. ${ }^{9)}$

In the present work, the effect of intercritical annealing parameters on the microstructure and consequently cold rolling properties of medium manganese AHSS were studied. Cold rolling studies and mechanical testing were performed to examine their potential as sheet products.

\section{Experimental Procedures}

\subsection{Material}

The steel ingots used throughout this work were supplied by CANMET-MTL (Hamilton, Ontario, Canada). Each melt was done in an induction furnace and cast in $100 \mathrm{~kg}$ ingots. The chemical compositions (in wt $\%$ ) are given in Table 1. The rationale for these compositions is given in reference. ${ }^{10)}$ After casting, the ingots were annealed for homogenization and were cut and hot rolled to $5.2 \mathrm{~mm}$ thickness plates by TUBITAK - MRC (Gebze, Kocaeli, Turkey). This was followed by a heat treatment and cold rolling step down to approximately $2 \mathrm{~mm}$ sheets in McGill University Steel Processing Laboratory conditions.

Table 1. The chemical composition of steel samples.

\begin{tabular}{ccccccc}
\hline Sample Nr. & C (\%) & Mn (\%) & Si (\%) & Al (\%) & Mo (\%) & Fe \\
\hline S-1 & 0.12 & 4.98 & 3.11 & 3.05 & 0.05 & bal. \\
S-2 & 0.19 & 4.96 & 3.09 & 2.99 & 0.03 & bal. \\
S-3 & 0.22 & 7.15 & 3.11 & 3.21 & 0.05 & bal. \\
S-4 & 0.20 & 10.02 & 3.17 & 3.19 & 0.06 & bal. \\
\hline
\end{tabular}




\subsection{Annealing}

Figure 1 shows the annealing schedule before cold rolling at different times (Annealing time $\left(\mathrm{t}_{\mathrm{an}}\right)$, from 10 to $30 \mathrm{~min}$ and temperatures $\left(\mathrm{T}_{\mathrm{an}}\right)$ ranging from 900 to $1200^{\circ} \mathrm{C}$, which is in the intercritical area (i.e. the austenite plus ferrite two phase region). The specimens were cooled to room temperature by water quenching (WQ) and air cooling (AC). The average cooling rate for air cooling and water was about 13 and $83^{\circ} \mathrm{C} / \mathrm{sec}$ respectively. A very low cooling rate (FC) of $0.5^{\circ} \mathrm{C} / \mathrm{s}$ was also conducted on specimens annealed at $1100^{\circ} \mathrm{C}$.

Initially, the main objective was to maximize the retained austenite with controlled deformation induced transformation behavior. Therefore, the heat treatment sequence was designed to generate a ferrite plus austenite structure by an intercritical anneal. The annealing was followed by various cooling rates designed to create a wide variety of microstructures, as listed in Table 2.

The annealing temperatures for $\mathrm{T}_{\mathrm{an}}-1$ were determined as $950^{\circ} \mathrm{C}$ for $\mathrm{S} 1,1020^{\circ} \mathrm{C}$ for $\mathrm{S} 2,1155^{\circ} \mathrm{C}$ for $\mathrm{S} 3$ and $1240^{\circ} \mathrm{C}$ for S4 according to the highest FCC content of phase diagrams, as can be seen from Fig. 2 and Table 3, which are calculated using the FactSage software with FSStel database. ${ }^{11)}$

The second annealing temperature ( $\left.\mathrm{T}_{\mathrm{an}} 2\right)$ was chosen as $900^{\circ} \mathrm{C}$ for all the steel compositions to generate finer polygonal ferrite and more stabilized retained austenite during air cooling. Finally, to evaluate the effect of grain size on the cold rolling properties of the two phase microstructures, high-temperature annealing $\left(\mathrm{T}_{\mathrm{an}}-3\right)$ followed by slow cool-

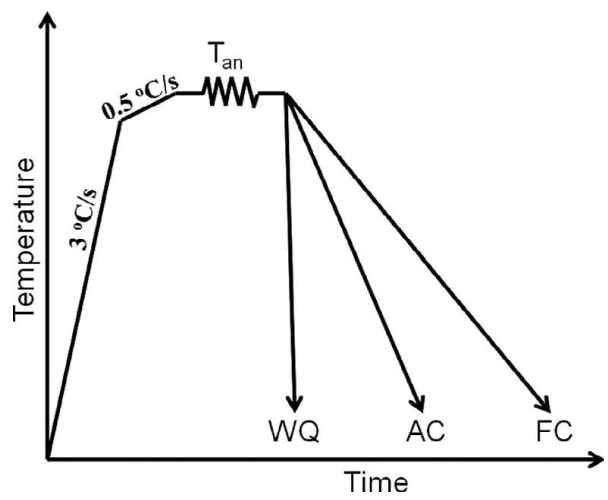

Fig. 1. Heat treatment schedule.

Fe - Mn Phase Diagram (0.1 C)

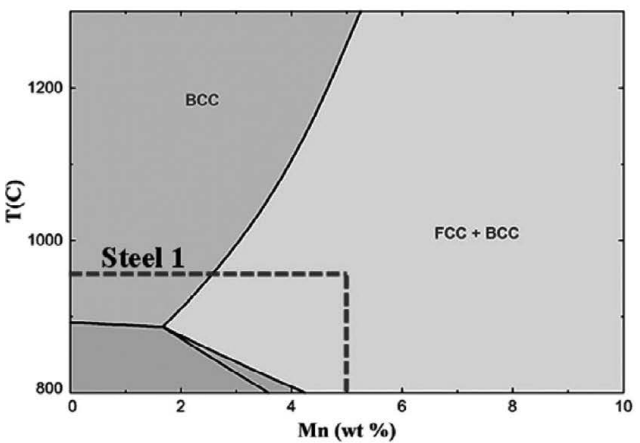

(a) ing $\left(0.5^{\circ} \mathrm{C} / \mathrm{s}\right)$ to room temperature, was conducted on the cold-rolled steel to obtain a coarse-grained ferrite plus pearlite microstructure.

\subsection{Cold Rolling}

Annealed plates were cold rolled at different deformation ratios with various reheating steps. Details of the rolling procedure and deformation process in each step before reheating are given in Table 4. The rolling direction was the same as for the hot rolling without reversing and a lubricant was applied on the rolls. The rolling speed was constant and calculated approximately around 35 revolutions per minute (RPM). Each reheating process was done for the steel sam-

Table 2. Detailed parameters used in various annealing process.

\begin{tabular}{|c|c|c|c|c|c|}
\hline Sample Nr. & Ann. $\mathrm{Nr}$ & $\mathrm{T}_{\mathrm{an}}\left({ }^{\circ} \mathrm{C}\right)$ & $t_{a n}(\min )$ & Cooling & Microstructure \\
\hline Steel 1 & $\mathrm{~T}_{\mathrm{an}}-1$ & 950 & 10 & WQ & $\mathrm{F}+\mathrm{M}+\mathrm{RA}$ \\
\hline Steel 1 & $\mathrm{~T}_{\mathrm{an}}-2$ & 900 & 15 & air & $\mathrm{F}+\mathrm{M} / \mathrm{B}+\mathrm{RA}$ \\
\hline Steel 1 & $\mathrm{~T}_{\mathrm{an}}-3$ & 1100 & 30 & $\mathrm{FC}$ & $\mathrm{F}+\mathrm{P} / \mathrm{B}+\mathrm{RA}$ \\
\hline Steel 2 & $\mathrm{~T}_{\mathrm{an}-1}$ & 1020 & 15 & WQ & $\mathrm{F}+\mathrm{M}+\mathrm{RA}$ \\
\hline Steel 2 & $\mathrm{~T}_{\mathrm{an}}-2$ & 900 & 15 & air & $\mathrm{F}+\mathrm{M} / \mathrm{B}+\mathrm{RA}$ \\
\hline Steel 2 & $\mathrm{~T}_{\mathrm{an}}-3$ & 1100 & 30 & $\mathrm{FC}$ & $\mathrm{F}+\mathrm{P} / \mathrm{B}+\mathrm{RA}$ \\
\hline Steel 3 & $\mathrm{~T}_{\mathrm{an}}-1$ & 1150 & 10 & WQ & $\mathrm{F}+\mathrm{M}+\mathrm{RA}$ \\
\hline Steel 3 & $\mathrm{~T}_{\mathrm{an}}-2$ & 900 & 15 & air & $\mathrm{F}+\mathrm{M} / \mathrm{B}+\mathrm{RA}$ \\
\hline Steel 3 & $\mathrm{~T}_{\mathrm{an}}-3$ & 1100 & 30 & $\mathrm{FC}$ & $\mathrm{F}+\mathrm{P} / \mathrm{B}+\mathrm{RA}$ \\
\hline Steel 4 & $\mathrm{~T}_{\mathrm{an}}-1$ & 1200 & 10 & WQ & $\mathrm{F}+\mathrm{M}+\mathrm{RA}$ \\
\hline Steel 4 & $\mathrm{~T}_{\mathrm{an}}-2$ & 900 & 15 & air & $\mathrm{F}+\mathrm{M} / \mathrm{B}+\mathrm{RA}$ \\
\hline Steel 4 & $T_{a n}-3$ & 1100 & 30 & $\mathrm{FC}$ & $\mathrm{F}+\mathrm{P} / \mathrm{B}+\mathrm{RA}$ \\
\hline
\end{tabular}

$\mathrm{T}_{\mathrm{an}}$ : annealing temperature; $\mathrm{t}_{\mathrm{an}}$ : annealing time; WQ: water quenching; $\mathrm{FC}$ : furnace cooling; F: ferrite, M: martensite, B: bainite, R. A.: retained austenite, P: pearlite

Table 3. FCC $\%$ content of steel compositions at elevated temperatures.

\begin{tabular}{ccc}
\hline Sample Nr. & $\mathrm{T}_{\mathrm{an}}-1\left({ }^{\circ} \mathrm{C}\right)$ & $\mathrm{FCC}(\%)$ \\
\hline Steel 1 & 950 & 12 \\
Steel 2 & 1020 & 25 \\
Steel 3 & 1150 & 42 \\
Steel 4 & 1200 & 62 \\
\hline
\end{tabular}

Fe- Mn Phase Diagram (0.2 C)

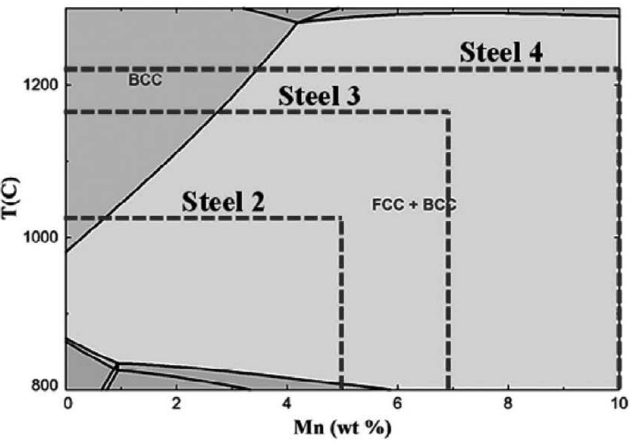

(b)

Fig. 2. Isopleths phase diagrams of two phase region $(\alpha+\gamma)$ with the intercritical annealing temperature of highest FCC content (a) S-1 and (b) S2, S3 and S4. 
ples to give maximum deformation ratio (before crack formation).

\subsection{Characterization}

In this study, characterization of the samples was made by means of microstructural examinations and mechanical tests. The microstructural examinations were carried out on a Nikon L150 optical microscope, Philips XL-30 field emis-

Table 4. Parameters of the cold rolling process.

\begin{tabular}{lrrrr}
\hline \multicolumn{1}{c}{ Steels } & S1 & S2 & S3 & S4 \\
\hline D. R. $(\%) \varepsilon_{t}=\left(\frac{\boldsymbol{t}-\boldsymbol{t}_{0}}{\boldsymbol{t}_{0}}\right) \times 100$ & 10 & 9 & 21 & 34 \\
N.P. & 19 & 14 & 21 & 24 \\
R.H. & 4 & 4 & 2 & 2 \\
Total Reduction $( \pm \%$ 5) & 40 & 35 & 45 & 60 \\
\hline
\end{tabular}

D. R.: Deformation ratio before reheating - $( \pm \% 5)$; N. P.: Number of passes before reheating

R.H.: Total number of reheating stages sion scanning electron microscope (FE-SEM), Bruker D8 X-ray difractometer and Philips CM200 200 kV transmission electron microscope (TEM). The volume percentage of the phases were calculated with the help of Clemex Captive image analyze software and an XRD intensity correlation method. ${ }^{12)}$ During the scan, the XRD detector position $(2 \theta)$ was $30^{\circ}$ and the apparatus was operated at $35 \mathrm{kV}$ accelerating voltage and $45 \mathrm{~mA}$ beam current.

For optical microscopy, the following etchants were used to reveal the microstructure and differentiate the phases clearly.

- $2 \%$ Nital

- $2 \%$ Nital followed by $10 \%$ aqueous sodium metabisulfite $\left(\mathrm{Na}_{2} \mathrm{~S}_{2} \mathrm{O}_{5}\right)$

- LePera's Etchant (equal portions of $1 \%$ aqueous $\mathrm{Na}_{2} \mathrm{~S}_{2} \mathrm{O}_{5}$ and $4 \%$ picral)

Etching by sodium metabisulfite makes ferrite gray, bainite or martensite black, and retained austenite white. ${ }^{13,14)}$ With LePera's Etchant, martensite or retained austenite appears white, bainite and pearlite appears black, ferrite appears grey or yellow (due to carbon concentration of sur-
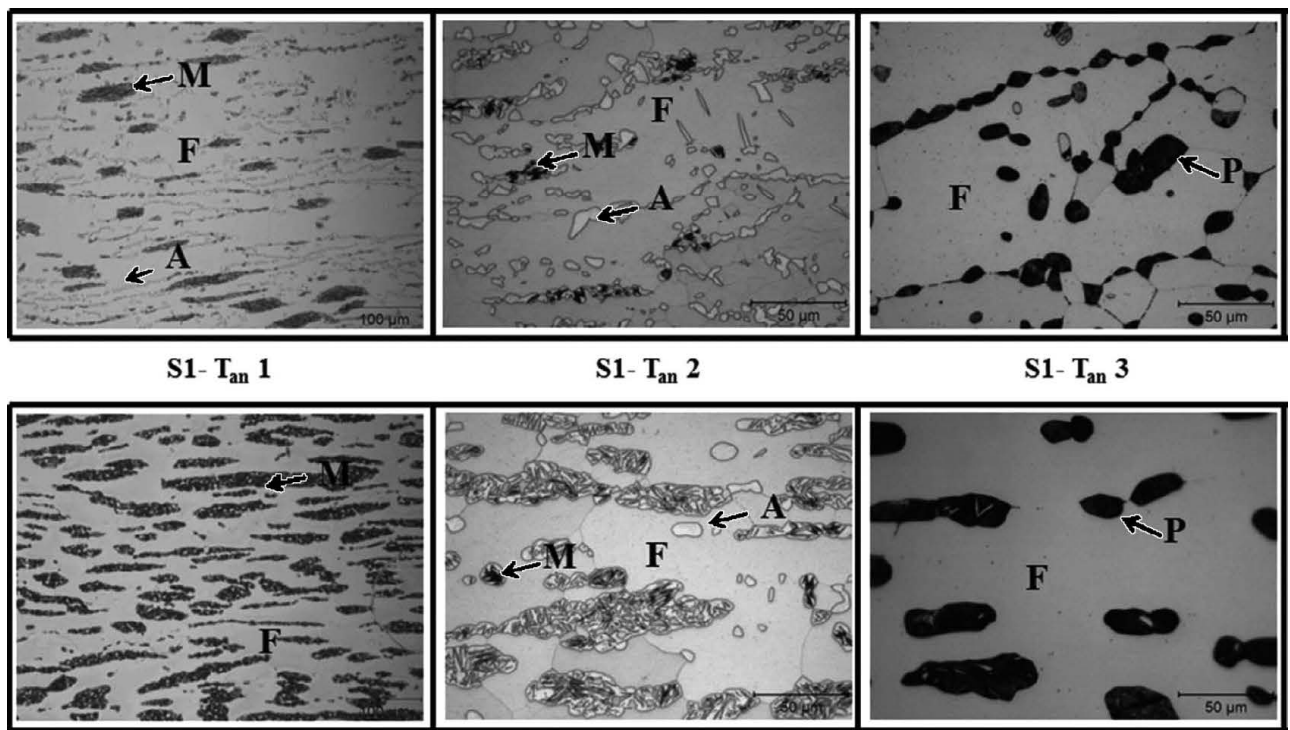

S1- $\mathbf{T}_{\mathrm{an}} 3$

S2- $\mathrm{T}_{\text {an }} 1$

S2- $T_{\text {an }} 2$
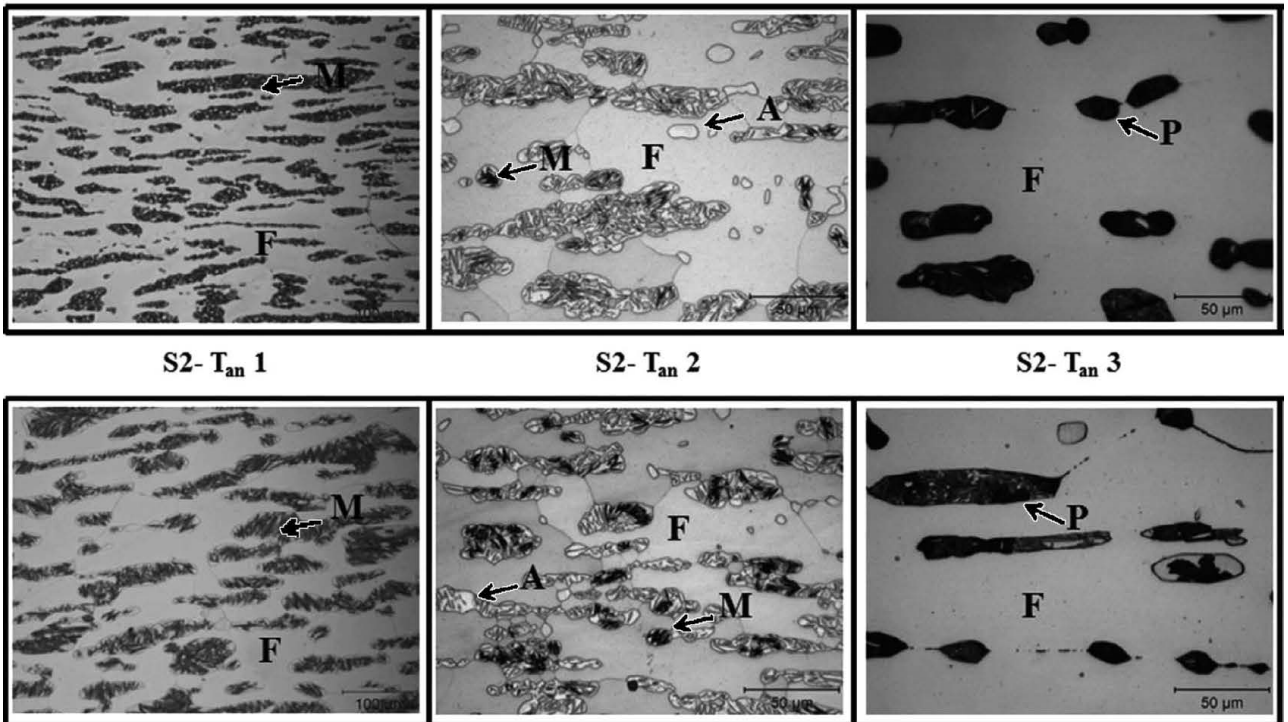

S2- $\mathbf{T}_{\text {an }} 3$
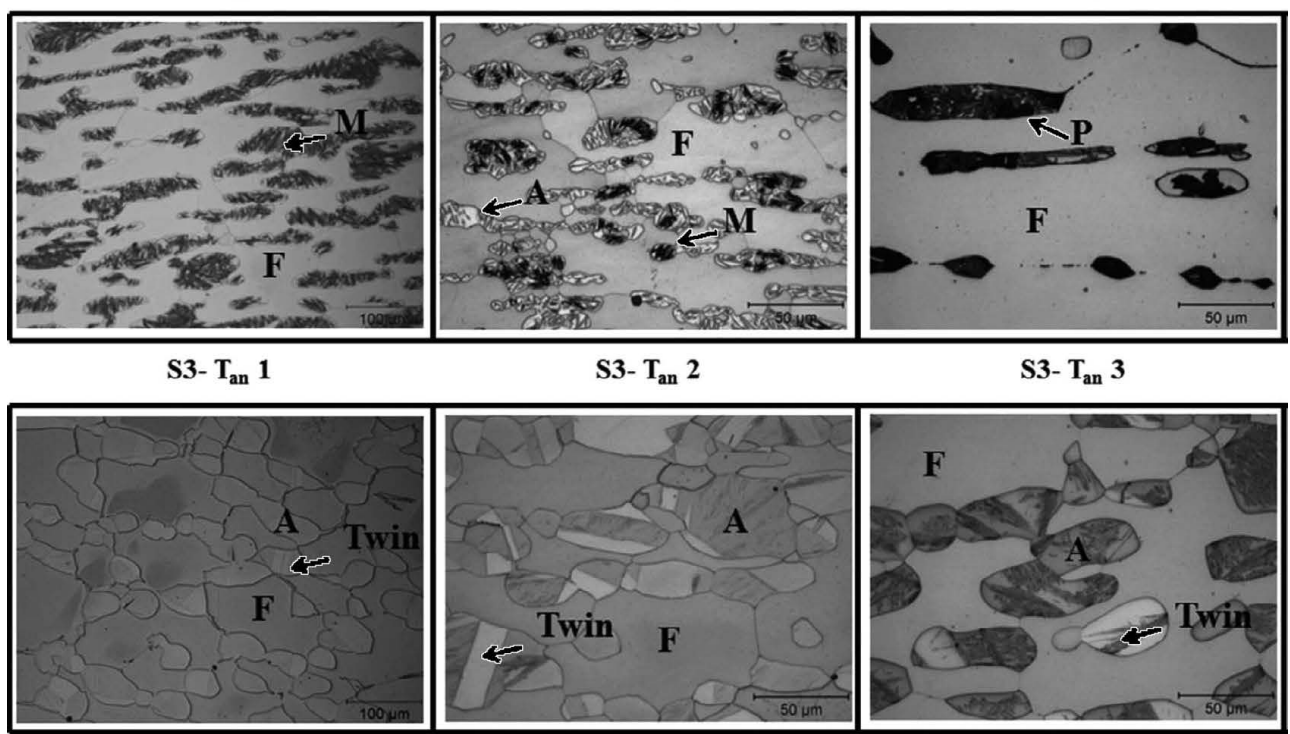

S4- $\mathbf{T}_{\text {an }} 1$

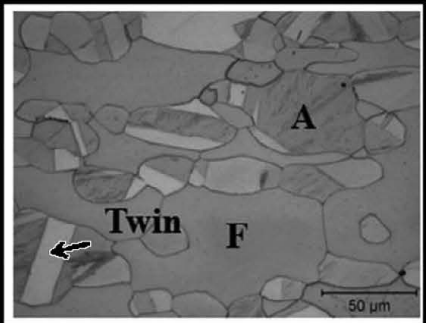

S4- $\mathbf{T}_{\text {an }} 2$
S3- T $T_{\text {an }} 3$

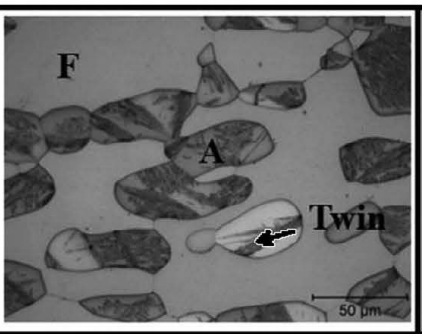

S4- $T_{a n} 3$

Fig. 3. The microstructures of annealed samples. 
face). ${ }^{13)}$ In most cases, although grain boundaries are not strongly etched, phases were clearly observed.

The mechanical tests were done by means of tensile tests. Tensile test samples were machined according to ASTM E8 sub-size standard and performed on a hydraulic MTS machine with a strain rate $0.01 \mathrm{~mm} / \mathrm{sec}$.

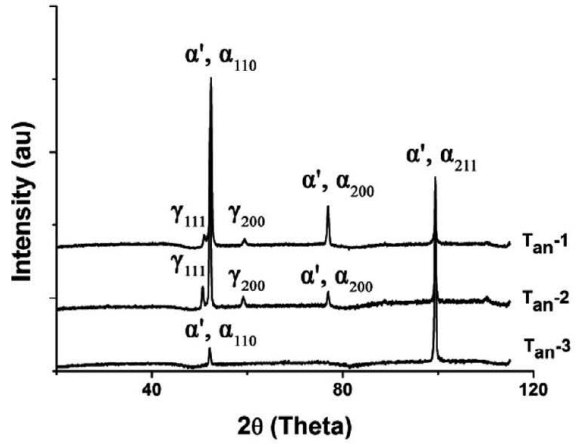

(a)

\section{Result}

\subsection{Microstructure}

The microstructures of the steels after $\mathrm{T}_{\mathrm{an}}-1, \mathrm{~T}_{\mathrm{an}}-2$ and $\mathrm{T}_{\mathrm{an}}-3$ annealing are given in Fig. 3. The volume percentage of the retained austenite was calculated by using image anal-

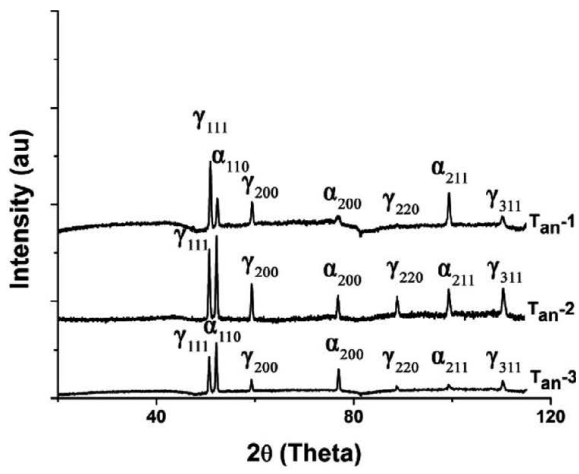

(b)

Fig. 4. Typical XRD paterns of (a) S2 which represents FMNA structure and (b) S4 for FADP structure.

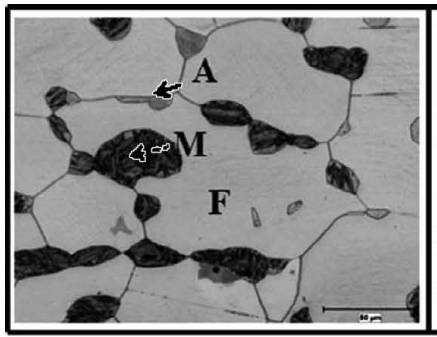

S1- $\mathbf{T}_{\text {an }} 1+\mathbf{C R}$

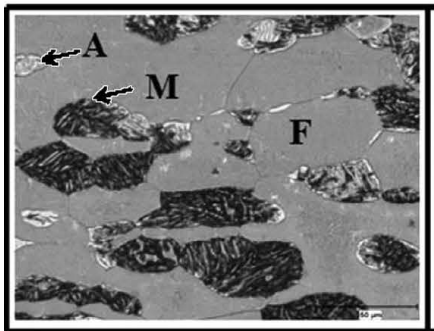

S2- $T_{a n} 1+C R$

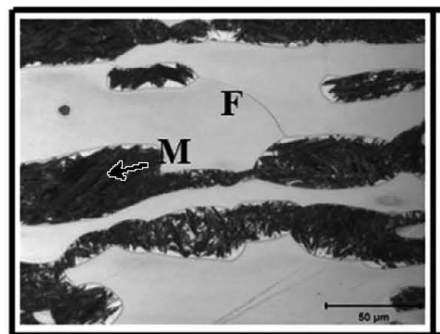

S3- $T_{\text {an }} 1+C R$

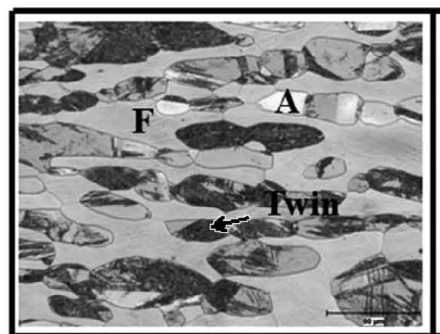

S4- $T_{\text {an }} 1+$ CR

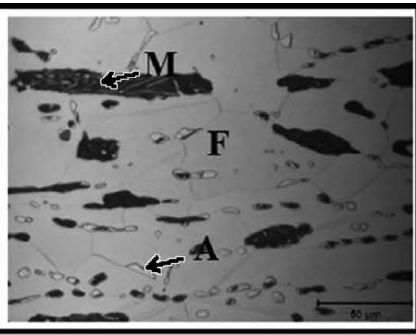

S1- $\mathbf{T}_{\text {an }} \mathbf{2}+\mathbf{C R}$

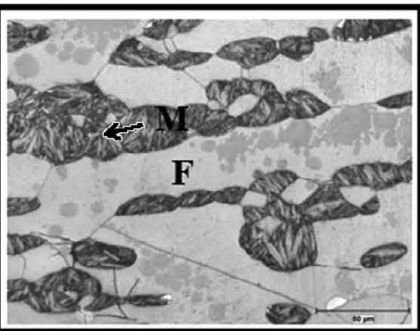

S2- $\mathbf{T}_{\text {an }} \mathbf{2}+\mathbf{C R}$

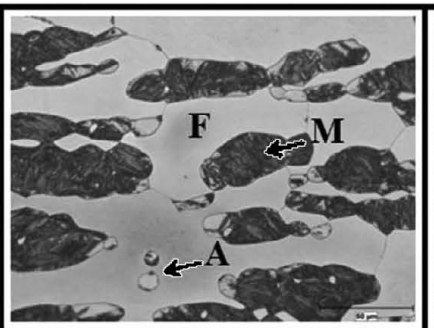

S3- T $_{\text {an }} 2+$ CR

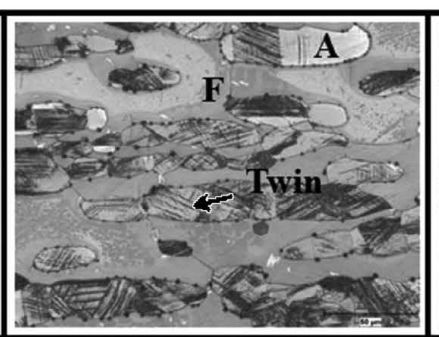

S4- $T_{a n} 2+C R$

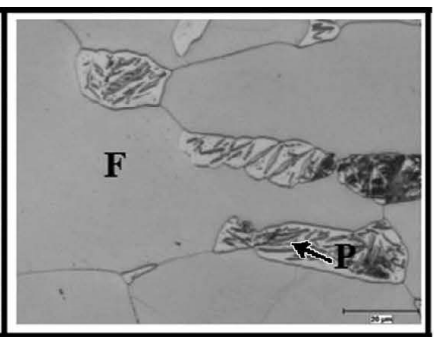

S1- $T_{a n} 3+C R$

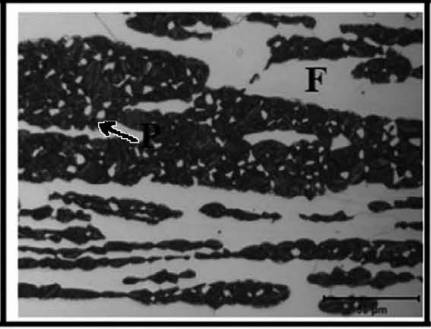

S2- $T_{\text {an }} 3+C R$

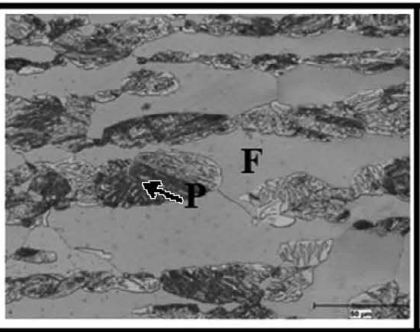

S3- $\mathbf{T}_{\mathrm{an}} \mathbf{3}+\mathbf{C R}$

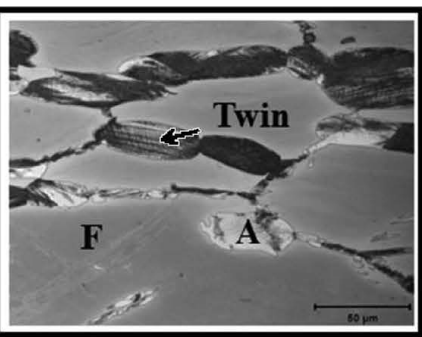

S4- $\mathbf{T}_{\mathrm{an}} \mathbf{3}+\mathbf{C R}$

Fig. 5. The microstructures of cold rolled samples. 
yses techniques and XRD intensity correlation method. Typical XRD patterns of the given microstructures presented in Fig. 4 and the quantified results of phase fractions, including those obtained by microscopy, are listed in Table 5 .

For S1, S2 and S3, after $\mathrm{T}_{\mathrm{an}}-1$, ferrite, martensite and retained austenite are observed. After annealing with $\mathrm{T}_{\mathrm{an}}-2$, the grain size is much finer as a result of the lower annealing temperature and, mainly result of the lower cooling rate, a very small amount of bainite forms, which is also, nucleated inside the austenite grains. However, it can be easily seen from the micrographs that the cooling rates of both annealing schedules have led to considerable levels of martensite during cooling from the two phase region. Quantitatively (Table 5) there is not much difference between these two heat treatments, but there is a tendency towards a higher retained austenite for $T_{a n}-2$. In the case of $T_{a n}-3$, the slow cooling rate has generated coarse pearlite as opposed to martensite and the ferrite volume fractions are higher.

Steel S4 is quite different in that $\mathrm{T}_{\mathrm{an}}-1$ leads to a duplex microstructure, which consists only of ferrite and austenite. In addition to this, a limited amount of annealing twins was detected in the austenitic phases. After $\mathrm{T}_{\mathrm{an}}-2$, the grain size is again much finer, and the duplex microstructure persists but apparently with more annealing twins. The $\mathrm{T}_{\mathrm{an}}-3$ treatment seems to be no different from the $\mathrm{T}_{\mathrm{an}}-2$ treatment. As will be discussed later, this seems to indicate that the austenite is much more stable in S4, which could be due to the Mn level. Quantitatively, $\mathrm{T}_{\mathrm{an}}-1$ yields the highest volume fraction of retained austenite.

The microstructures of cold rolled samples are given in Fig. 5, typical XRD patterns of the given microstructures presented in Fig. $\mathbf{6}$ and the quantitative values are listed in Table 6. The important feature is the behavior of the retained austenite. In the case of S1, S2 and S3, the retained austenite transformed to martensite (either $\alpha^{1}$ or $\varepsilon$ ) due to the cold rolling procedures, except for $\mathrm{S} 3$ in the $\mathrm{T}_{\mathrm{an}}-1$ condition, in which there appears to be no strain induced transformation of the retained austenite. For, the retained austenite for $\mathrm{S} 1$ and $\mathrm{S} 2$ in the $\mathrm{T}_{\mathrm{an}}-1$ condition, the retained austenite is approximately halved, after cold rolling. For $\mathrm{T}_{\mathrm{an}}{ }^{-}$ 2, S1, S2 and S3 all undergo a strain induced transformation, with more retained austenite transforming to martensite.

For S4, cold rolling also transformed some of the retained austenite to martensite, as shown in Fig. 6 and Table 6, with more transformation occurring for $\mathrm{T}_{\mathrm{an}}-2$. Moreover, defor- mation twins in the austenite were seen in all cold rolled samples, with twins and martensites occasionally seeming to co-exist in the same austenite grain.

Finally, Fig. 7 show the microstructures of tensile tested samples. The deformation due to tensile testing seems to have less influence on the final microstructures, in contrast to the cold rolled specimens. But the quantified results of phase fractions (Table 7) show that in some cases austenite has transformed (to martensite). Typical XRD patterns of the given microstructures can be seen in Fig. 8.

\subsection{Tensile Test Results}

Figure 9 shows typical stress -strain diagrams of uniaxial tensile tests after annealing treatments of hot rolled samples. The overall mechanical properties measured by these tensile

Table 5. The volume fraction of phase for steel compositions after annealing process.

\begin{tabular}{cccc|ccc|ccc}
\hline \multirow{2}{*}{$\begin{array}{c}\text { Steel } \\
\text { Nr. }\end{array}$} & \multicolumn{3}{c}{$\mathrm{T}_{\mathrm{an}}-1$} & \multicolumn{4}{c}{$\mathrm{T}_{\mathrm{an}}-2$} \\
\cline { 2 - 9 } & $\mathrm{F}_{\mathrm{v}} \%$ & $\mathrm{~A}_{\mathrm{v}} \%$ & $\mathrm{M}_{\mathrm{v}} \%$ & $\mathrm{~F}_{\mathrm{v}} \%$ & $\mathrm{~A}_{\mathrm{v}} \%$ & $\mathrm{M}_{\mathrm{v}}+\mathrm{B}_{\mathrm{v}} \%$ & $\mathrm{~F}_{\mathrm{v}} \%$ & $\mathrm{~A}_{\mathrm{v}} \%$ & $\mathrm{P}_{\mathrm{v}} \%$ \\
\hline $\mathrm{S}-1$ & 74 & 15.2 & 10.8 & 76 & 17 & 4 & 84 & - & 16 \\
$\mathrm{~S}-2$ & 63 & 9.1 & 27.9 & 60 & 14 & 24 & 86 & - & 14 \\
$\mathrm{~S}-3$ & 51 & 17.1 & 31.9 & 57 & 20.5 & 22.5 & 87 & 1.7 & 11.3 \\
$\mathrm{~S}-4$ & 43 & 53 & 4 & 48 & 47 & 5 & 47 & 47.5 & 5.5 \\
\hline
\end{tabular}

${ }^{*} \mathrm{~F}_{\mathrm{v}} \%$ : Ferrite volume fraction; $\mathrm{A}_{\mathrm{v}} \%$ : Austenite volume fraction; $\mathrm{M}_{\mathrm{v}} \%$ : Martensite volume fraction; $\mathrm{B}_{\mathrm{v}} \%$ : Bainite volume fraction; $\mathrm{P}_{\mathrm{v}} \%$ : Pearlite volume fraction

Table 6. The change of RA volume fraction after cold rolling process.

\begin{tabular}{ccc|cc|cc}
\hline & \multicolumn{2}{c}{$\mathrm{T}_{\mathrm{an}-1}$} & \multicolumn{2}{c}{$\mathrm{T}_{\mathrm{an}-2}$} & \multicolumn{2}{c}{$\mathrm{T}_{\mathrm{an}-3}$} \\
\cline { 2 - 7 } & $\begin{array}{c}\text { Before } \\
\text { C.R. }\end{array}$ & $\begin{array}{c}\text { After } \\
\text { C.R. }\end{array}$ & $\begin{array}{c}\text { Before } \\
\text { C.R. }\end{array}$ & $\begin{array}{c}\text { After } \\
\text { C.R. }\end{array}$ & $\begin{array}{c}\text { Before } \\
\text { C.R. }\end{array}$ & $\begin{array}{c}\text { After } \\
\text { C.R. }\end{array}$ \\
\cline { 2 - 7 } & $\mathrm{A}_{\mathrm{v}} \%$ & $\mathrm{~A}_{\mathrm{v}} \%$ & $\mathrm{~A}_{\mathrm{v}} \%$ & $\mathrm{~A}_{\mathrm{v}} \%$ & $\mathrm{~A}_{\mathrm{v}} \%$ & $\mathrm{~A}_{\mathrm{v}} \%$ \\
\hline S-1 & 15.2 & 7.2 & 17 & 4.3 & - & 1.3 \\
S-2 & 9.1 & 4.8 & 14 & 2.6 & - & - \\
S-3 & 17.1 & 13.7 & 20.5 & 5.7 & 1.7 & 2.1 \\
S-4 & 53 & 32.7 & 47 & 23.2 & 47.5 & 28.4 \\
\hline
\end{tabular}

${ }^{*} \mathrm{~F}_{\mathrm{v}} \%$ : Ferrite volume fraction; $\mathrm{A}_{\mathrm{v}} \%$ : Austenite volume fraction; $\mathrm{M}_{\mathrm{v}} \%$ : Martensite volume fraction; $\mathrm{B}_{\mathrm{v}} \%$ : Bainite volume fraction; $\mathrm{P}_{\mathrm{v}} \%$ : Pearlite volume fraction

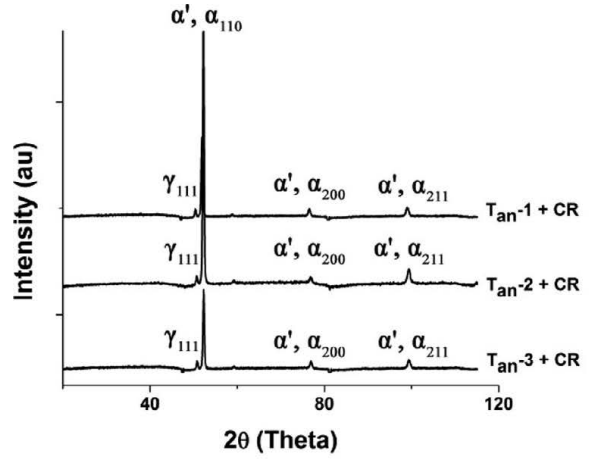

(a)

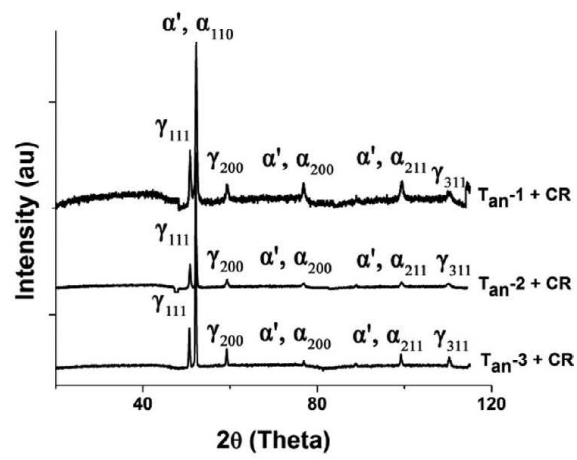

(b)

Fig. 6. Typical XRD paterns of cold rolled (a) S3 which represents deformed FMNA structure and (b) S4 for deformed FADP structure. 


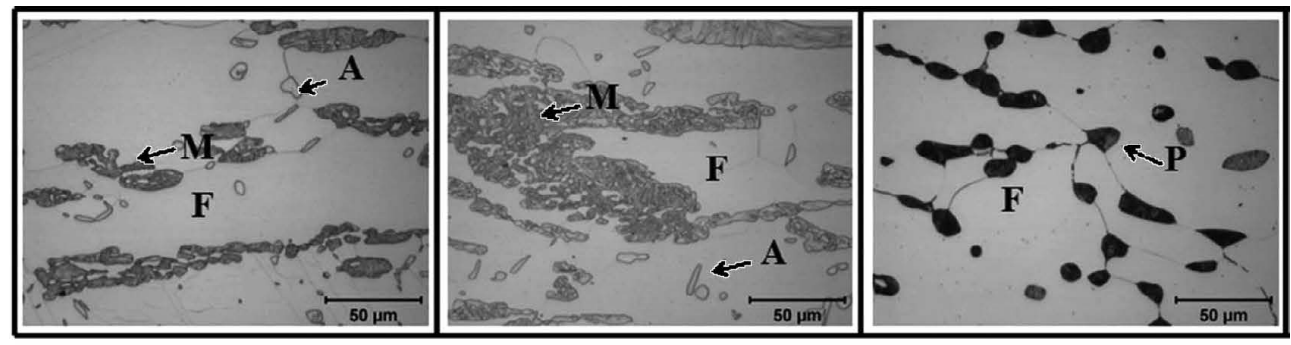

S1- $T_{a n} 1+$ Tensile

S1- $\mathbf{T}_{\mathrm{an}} \mathbf{2}+$ Tensile

S1- $\mathbf{T}_{a n} 3+$ Tensile
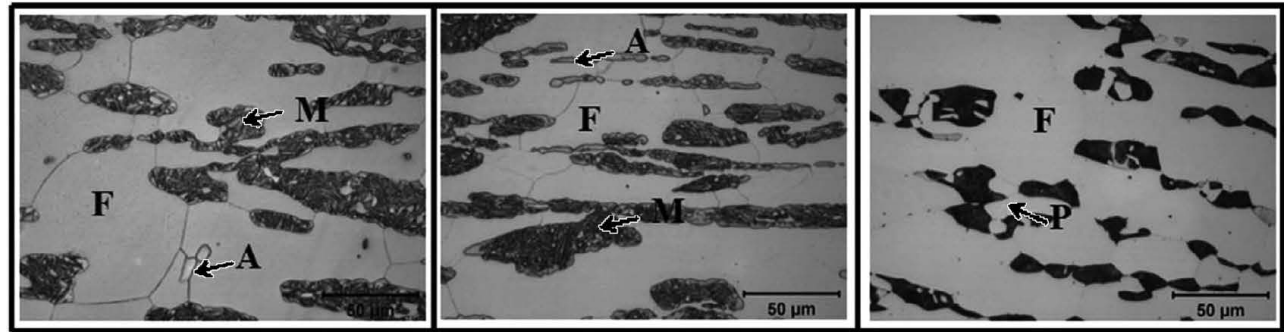

S2- $\mathbf{T}_{\mathrm{an}} \mathbf{1}+$ Tensile

S2- $\mathbf{T}_{\mathrm{an}} \mathbf{2}+$ Tensile

S2- $\mathbf{T}_{\text {an }} 3+$ Tensile
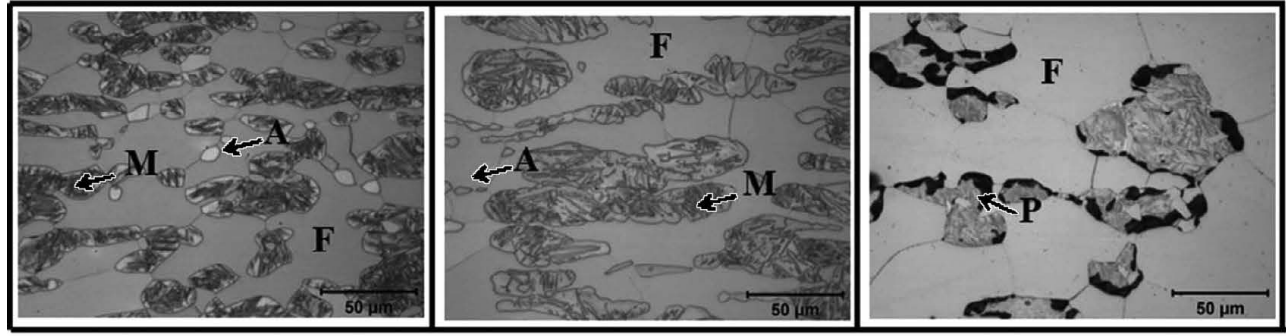

S3- $\mathbf{T}_{\text {an }} 1+$ Tensile

S3- $\mathbf{T}_{\text {an }} \mathbf{2}+$ Tensile

S3- $\mathbf{T}_{\text {an }} 3+$ Tensile

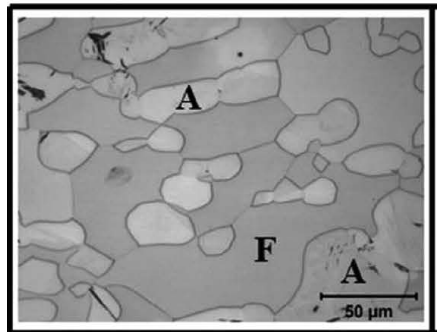

S4- $T_{\text {an }} 1+$ Tensile
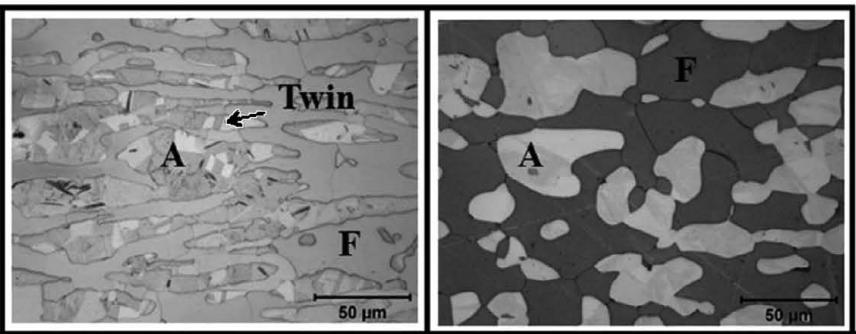

S4- $T_{a n} 2+$ Tensile

S4- $\mathbf{T}_{\mathrm{an}} 3+$ Tensile

Fig. 7. The microstructures of tensile test samples.

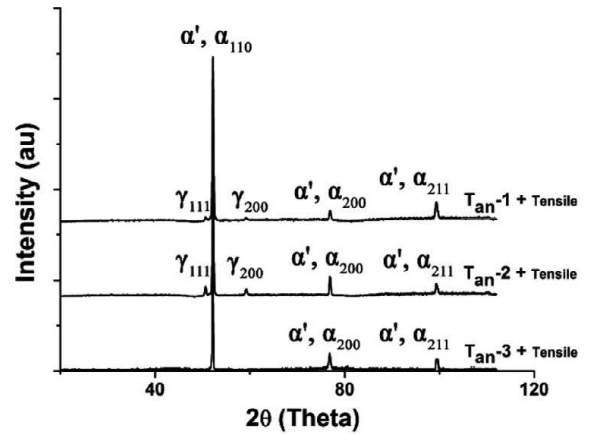

(a)

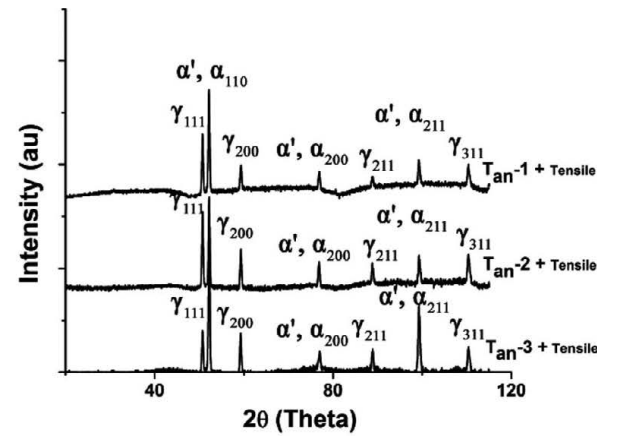

(b)

Fig. 8. Typical XRD paterns of tensile test samples; (a) S1 represents for FMNA structure and (b) S4 for FADP structure.

tests are given in Table 8 by means of maximum strength $\left(\sigma_{\text {UTS }}\right)$ and total elongation ( $\left.\% \varepsilon_{\text {total }}\right)$ values. In general, it was observed that increasing annealing time and temperature decreased the strength of these materials significantly, but only slightly increased the ductility. After annealing at $\mathrm{T}_{\mathrm{an}}-1$ and $\mathrm{T}_{\mathrm{an}}-2$, a tensile strength of $800-900 \mathrm{MPa}$ and total elongation of about 10 to $30 \%$ was obtained. Tensile strength decreased strongly after $\mathrm{T}_{\mathrm{an}}-3$ for all steel compositions to 500-700 MPa but the total elongation remained largely unchanged (15-25\%). 
Table 7. The change of RA volume fraction after tensile test.

\begin{tabular}{ccc|cc|cc}
\hline & \multicolumn{2}{c}{$\mathrm{T}_{\mathrm{an}-1}$} & \multicolumn{2}{c}{$\mathrm{T}_{\mathrm{an}-2}$} & \multicolumn{2}{c}{$\mathrm{T}_{\mathrm{an}}-3$} \\
\cline { 2 - 7 } & $\begin{array}{c}\text { Before } \\
\text { T.T. }\end{array}$ & $\begin{array}{c}\text { After } \\
\text { T.T. }\end{array}$ & $\begin{array}{c}\text { Before } \\
\text { T.T. }\end{array}$ & $\begin{array}{c}\text { After } \\
\text { T.T. }\end{array}$ & $\begin{array}{c}\text { Before } \\
\text { T.T. }\end{array}$ & $\begin{array}{c}\text { After } \\
\text { T.T. }\end{array}$ \\
\cline { 2 - 7 } & $\mathrm{A}_{\mathrm{v}} \%$ & $\mathrm{~A}_{\mathrm{v}} \%$ & $\mathrm{~A}_{\mathrm{v}} \%$ & $\mathrm{~A}_{\mathrm{v}} \%$ & $\mathrm{~A}_{\mathrm{v}} \%$ & $\mathrm{~A}_{\mathrm{v}} \%$ \\
\hline S-1 & 15.2 & 6.2 & 17 & 8.6 & - & - \\
S-2 & 9.1 & 7.5 & 14 & 5.8 & - & - \\
S-3 & 17.1 & 12.5 & 20.5 & 17.3 & 1.7 & 1.6 \\
S-4 & 53 & 42.3 & 47 & 45.1 & 47.5 & 30.9 \\
\hline
\end{tabular}

${ }^{*} \mathrm{~F}_{\mathrm{v}} \%$ : Ferrite volume fraction; $\mathrm{A}_{\mathrm{v}} \%$ : Austenite volume fraction; $\mathrm{M}_{\mathrm{v}} \%$ : Martensite volume fraction; $\mathrm{B}_{\mathrm{v}} \%$ : Bainite volume fraction; $\mathrm{P}_{\mathrm{v}} \%$ : Pearlite volume fraction

Table 8. Tensile test results of annealed samples.

\begin{tabular}{ccc|cc|cc|cc}
\hline \multicolumn{3}{c}{ Hot Rolled Tensile } & \multicolumn{3}{c}{$\mathrm{T}_{\mathrm{an}}-1+$ Tensile } & \multicolumn{2}{c}{$\mathrm{T}_{\mathrm{an}}-2+$ Tensile } & \multicolumn{2}{c}{$\mathrm{T}_{\mathrm{an}}-3+$ Tensile } \\
\cline { 2 - 9 } & UTS & $\% \varepsilon_{\text {total }}$ & UTS & $\% \varepsilon_{\text {total }}$ & UTS & $\% \varepsilon_{\text {total }}$ & UTS & $\% \varepsilon_{\text {total }}$ \\
\hline S-1 & 855 & 5.07 & 799 & 17 & 858 & 15 & 674 & 21 \\
S-2 & 1008 & 3.06 & 828 & 17 & 941 & 11 & 561 & 16 \\
S-3 & 1044 & 2.2 & 868 & 20 & 928 & 15 & 497 & 18 \\
S-4 & 827 & 6 & 868 & 31 & 873 & 23 & 685 & 25 \\
\hline
\end{tabular}
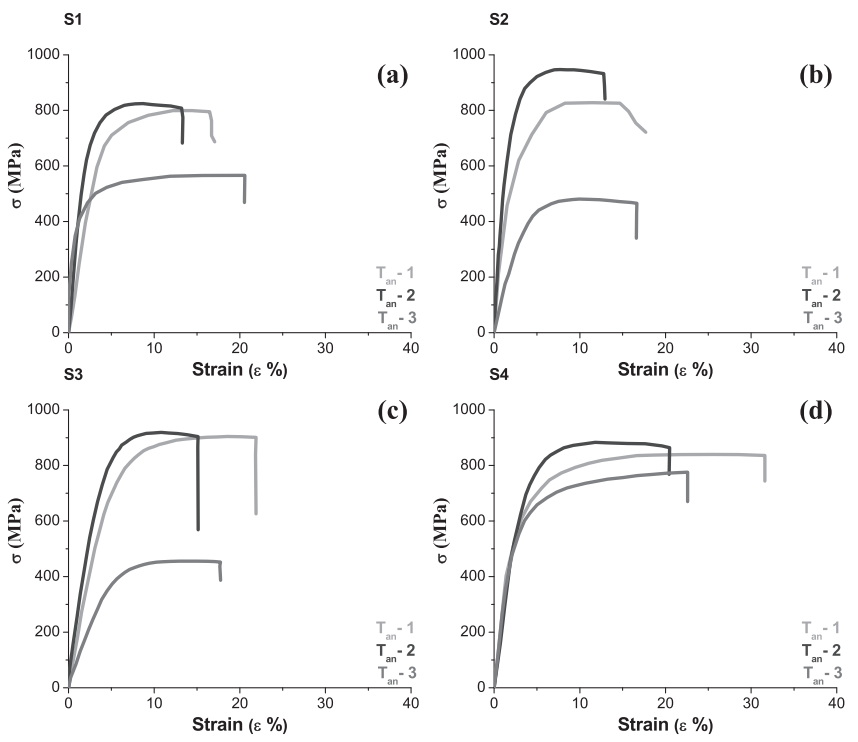

(c)

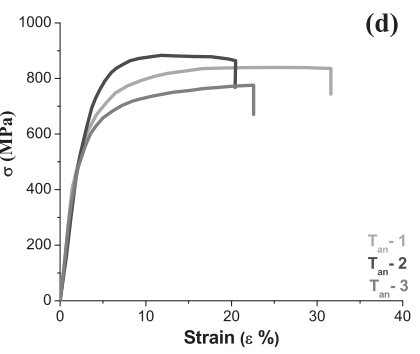

Fig. 9. Engineering stress - strain diagrams of steel samples; (a) $\mathrm{S} 1$, (b) S2, (c) S3 and (d) S4.

\section{Discussion}

\subsection{Effect of Composition on the Microstructure}

The compositional differences appeared to have generated two classes of microstructure, a multiphase structure that comprises ferrite, martensite/bainite and retained austenite (S1, S2 and S3) and a duplex retained austenite plus ferrite microstructure (S4). The key difference seems to be the increase of Mn from that of S3 (about 7\% Mn) to S4 (about $10 \% \mathrm{Mn})$.

Figure 10 represents the FactSage prediction of the change of austenite and its carbon and manganese content as a function of the temperature for the steel compositions. The FactSage predictions for the equilibrium structures certainly indicate a significant increase in austenite at corresponding annealing temperatures (Fig. 10), but this does not in itself explain the different room temperature microstructures, i.e. the relatively strong stability of the austenite formed during annealing at this level of $\mathrm{Mn}$. The $\mathrm{C}$ levels of the austenite formed are important because these control the stability of the austenite; a higher $\mathrm{C}$ level indicates an austenite more likely to be retained. However, the FactSage predictions for $\mathrm{C}$ in the austenite during annealing, which are also illustrated in Fig. 10(a), show that S4 has the lowest $\mathrm{C}$ at all temperatures, but it has the highest retained austenite. On the other hand, the predicted Mn levels in the austenite at the annealing temperatures is much higher in S4 than the other alloys, and it may be that this is the critical alloying element related to retained austenite levels (Fig. 10(b)). $9,10,15)$

The levels of retained austenite in S1, S2 and S3 are similar to those of other medium manganese (5 to 7\%) containing steels, ${ }^{10,15,16)}$ in which significant quantities of retained austenite were not produced.

In order to validate the above predictions from FactSage, $\mathrm{C}$ and $\mathrm{Mn}$ levels in the retained austenite of S2, S3 and S4 were measured for $\mathrm{T}_{\mathrm{an}}-1$ and $\mathrm{T}_{\mathrm{an}}-2$ by EPMA using WDS detectors. The results are plotted in Figs. 10(a) and 10(b). Although $\mathrm{T}_{\mathrm{an}}-2$ is followed by air cooling, which may lead to some partitioning of the elements during cooling, the general trend due to temperature and composition will be maintained. The measured results indicate that the FactSage predicted trends are matched, therefore reinforcing the hypothesis that $\mathrm{Mn}$ is the critical element in obtaining the significant increase in retained austenite from S3 to S4.

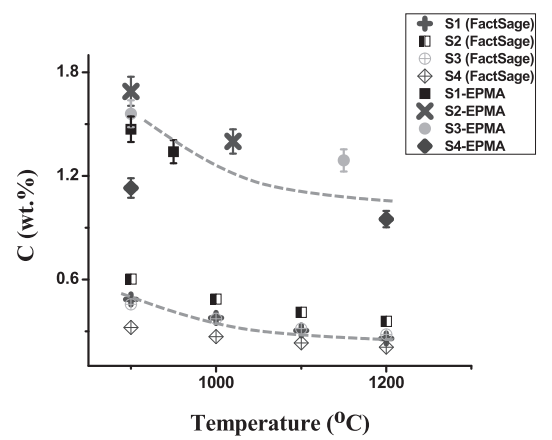

(a)

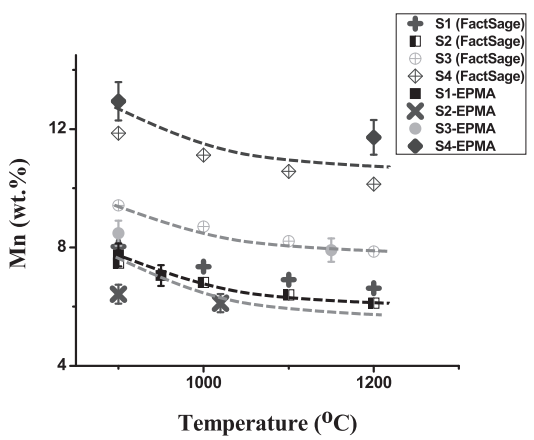

(b)

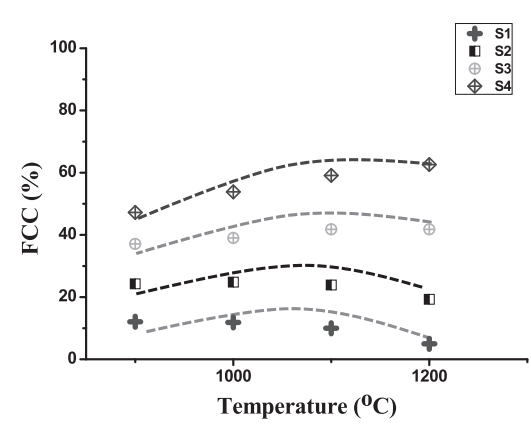

(c)

Fig. 10. The FactSage prediction for the change of (a) carbon and (b) manganese content in (c) austenite as a function of the temperature (depicted with EPMA results of $\mathrm{C}$ and $\mathrm{Mn}$ content in retained austenite) 


\subsection{Effect of Annealing Temperature and Cooling Rate on the Microstructure}

When the effects of $\mathrm{T}_{\mathrm{an}}-1$ and $\mathrm{T}_{\mathrm{an}}-2$ are compared for $\mathrm{S} 1$, $\mathrm{S} 2$ and $\mathrm{S} 3$, in contrast to the water quenched specimens, air cooled samples seem to be little affected, with regard to the volume fraction of the second phase, with change in intercritical annealing temperature. This is because, with decreasing intercritical annealing temperatures at $\mathrm{T}_{\mathrm{an}}-2$, although the volume fraction of austenite decreases, the carbon content of this austenite increases (Fig. 10), leading to more stabilized retained austenite with less martensitic transformation occurring during cooling. It can be seen from the EPMA - WDS elemental mapping of $\mathrm{C}$ for $\mathrm{S} 2$ after $\mathrm{T}_{\mathrm{an}}{ }^{-}$ 1 and $\mathrm{T}_{\mathrm{an}}-2$ annealing (Fig. 11), that the thermally transformed phase nucleating inside the retained austenite islands can be differentiated from retained austenite. There is a much greater difference in $\mathrm{C}$ levels between the RA and the nucleated phase within the austenite in the case of $\mathrm{T}_{\mathrm{an}}-2$. This suggests that the phase formed in the austenite due to $\mathrm{T}_{\mathrm{an}}-2$, i.e. after air cooling as opposed to quenching, is bainite rather than martensite.

For both air cooling and water quenching, the volume fraction of the secondary phases (austenite + martensite) was nearly constant irrespective of the annealing temperatures. Thus the microstructure of $\mathrm{T}_{\mathrm{an}}-1$ and $\mathrm{T}_{\mathrm{an}}-2$ resembles a TRIP steel phase formation, but with martensite mostly substituting for the bainite in $\mathrm{T}_{\mathrm{an}}-1$, and the martensite/bainite surrounded by austenite (Fig. 12). On the other hand, for the $\mathrm{T}_{\mathrm{an}}-3$ annealing treatment, the very slow cooling rate leads to pearlite, no martensite and slightly coarser grains. In addition to this, in the case of S-1 and S-2, when the austenite is quenched from a low temperature, the nonequilibrium concentration of carbon in solid solution is higher, which should increase the SFE in the FCC phase.
In case of S-4, all annealing schedules resulted in a duplex microstructure of ferrite and austenite, with a limited number of annealing twins and very small amount of martensite in the austenitic phases. The most interesting aspect of S4 is that the different cooling rates did not make any significant difference on the amount of retained austenite. As can be seen from Fig. 13, S4 retained a significant level of austenite at room temperature even after furnace cooling. Note that FactSage predicts no austenite at equilibrium at room temperature. Moreover, the retained austenite volume

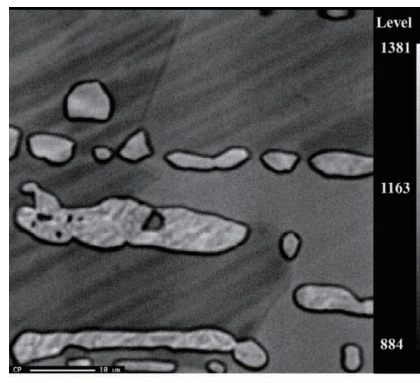

(a)

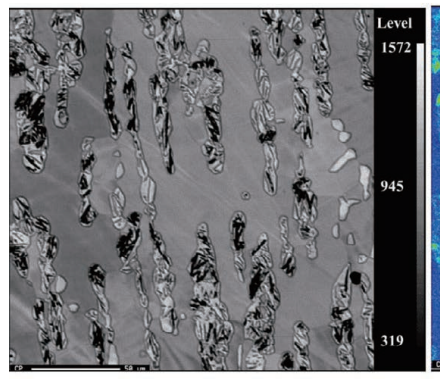

(c)

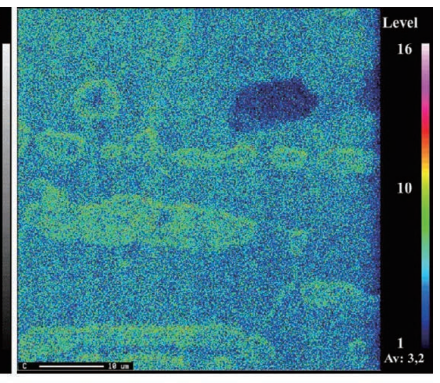

(b)

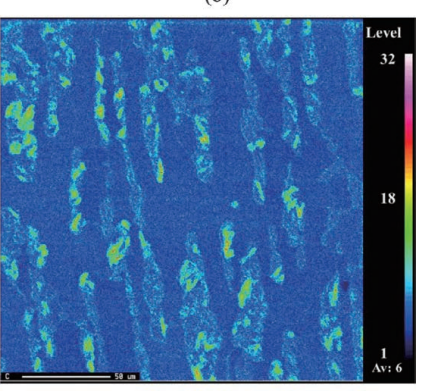

(d)
Fig. 11. The BSE images and EPMA-WDS carbon mapping of S2 after (a), (b) $\mathrm{T}_{a n}-1$ annealing and (c), (d) $\mathrm{T}_{\mathrm{an}}-2$ annnealing.
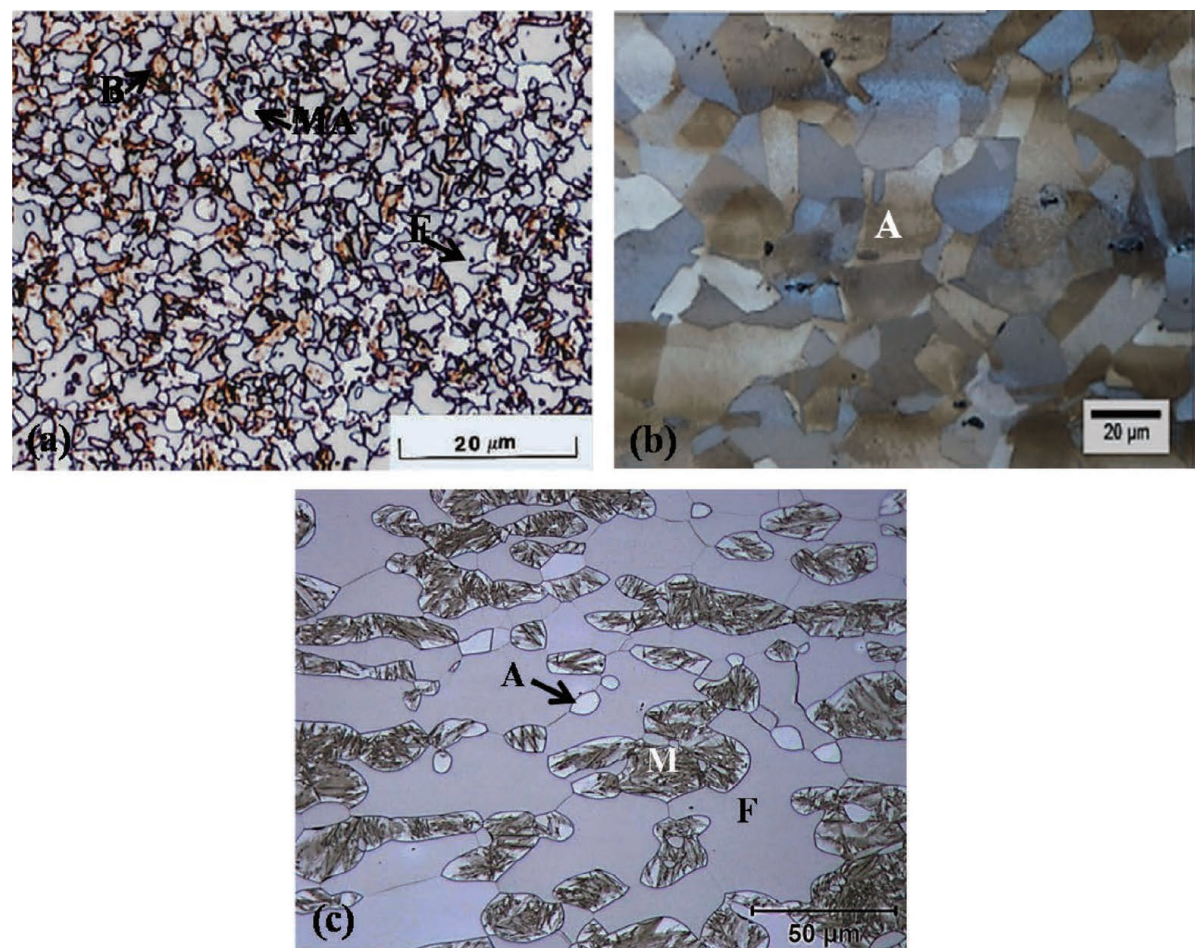

Fig. 12. The microstructure of (a) classic TRIP steel composition $\left.(0.27 \mathrm{C}, 1.4 \mathrm{Mn}, 1.4 \mathrm{Si}),{ }^{17}\right)$ (b) candidate 3 rd Generation AHSS composition $(0.23 \mathrm{C}-5.35 \mathrm{Mn}-3.5 \mathrm{Al}-2.89 \mathrm{Si})^{15)}$ and (c) S3 composition $(0.22 \mathrm{C}-7.15 \mathrm{Mn}-3.21 \mathrm{Al}-3.11 \mathrm{Si})$ at $\mathrm{T}_{\mathrm{an}}$-1conditions. 

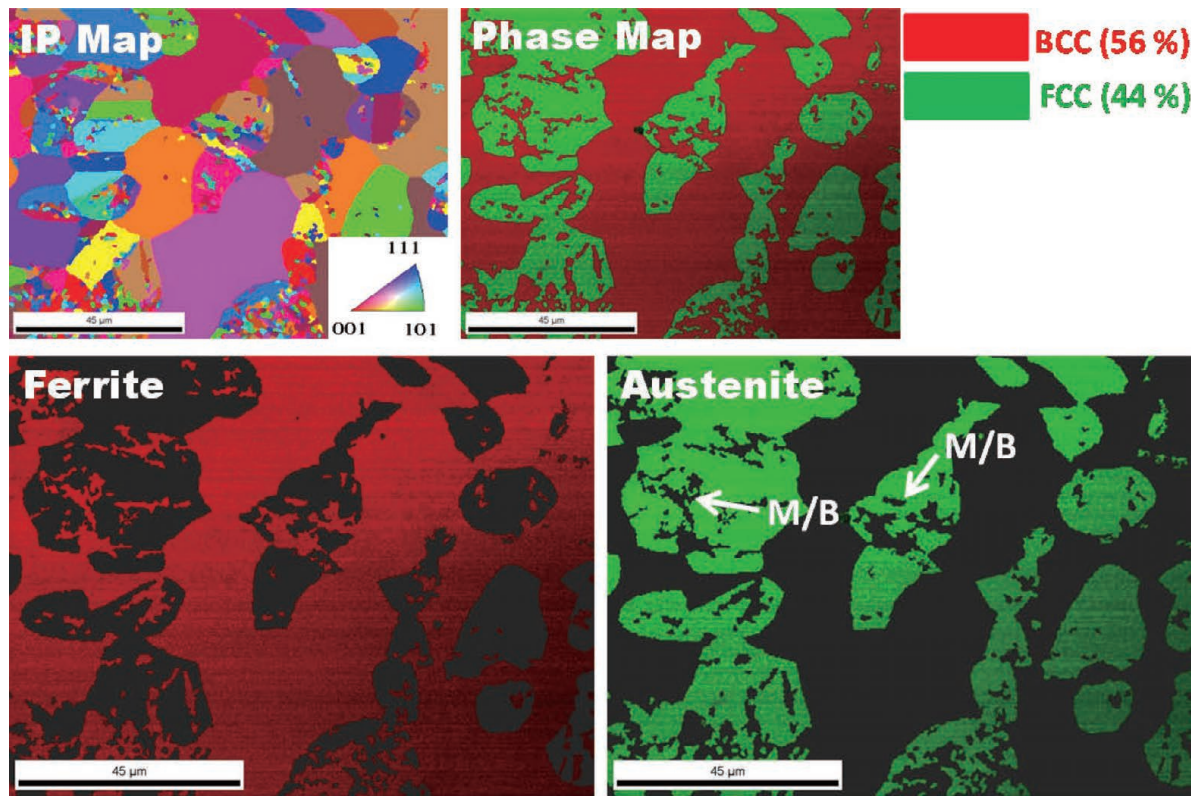

Fig. 13. The EBSD map of $\mathrm{S} 4$ after $\mathrm{T}_{\mathrm{an}}-3$ annealing: Inverse pole figure and phase distribution (ferrite and retained austenite).

fractions of $\mathrm{S} 4$ after $\mathrm{T}_{\mathrm{an}}-1, \mathrm{~T}_{\mathrm{an}}-2$ and $\mathrm{T}_{\mathrm{an}}-3$ were more or less close to each other as was seen in Table 5 .

\subsection{Effect of Annealing Temperature and Cooling Rate on the Mechanical Properties}

The results of tensile tests conducted on hot rolled and annealed plates and are given in Table 8 to show the evolution of mechanical properties at each processing stage. It can be seen that the mechanical properties of steels are not only connected to the increase of retained austenite also related with the transformed martensite volumes. As a general trend the higher the martensite content the higher is the strength but the lower ductility. On the contrary, with increasing Mn and the retained austenite content, higher ductility was observed.

In particular, the maximum elongation observed correlated with retained austenite as well as $\mathrm{Mn}$ (wt\%) content, with S4 (FADP microstructure) demonstrating reasonably high strength. The highest strength was obtained with S2 (FMNA microstructure) in $\mathrm{T}_{\mathrm{an}}-2$ annealing, which has the highest martensite volume fraction. The trend of decreasing strength and increasing ductility generally corresponds to increasing martensite volume fraction and decreasing Mn (wt\%) content as well as retained austenite volume fraction (Fig. 14).

Indeed, the reason for the high elongation values in S4 or FADP structure is believed to be the strain induced transformation take place during deformation (either mechanical testing or cold rolling) (Fig. 5). On the other hand, when $\mathrm{T}_{\text {an- }}$ 1 and $\mathrm{T}_{\mathrm{an}}-2$ compared to each other, for FMNA structure, the relationship between strength/ductility and structure might be due to a difference in the carbon levels of the martensites and/or bainite; i.e. there was a higher carbon level in the specimen intercritically annealed and air cooled samples (Fig. 11). Hence it can be claim that the stability of retained austenite mostly related with Mn content during thermal processing and as well as $\mathrm{C}$ content during deformation.

\subsection{Effect of Cold Rolling}

Cold rolling led retained austenite to strain induced mar-

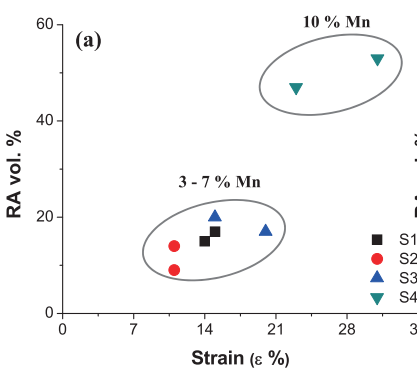

(a)

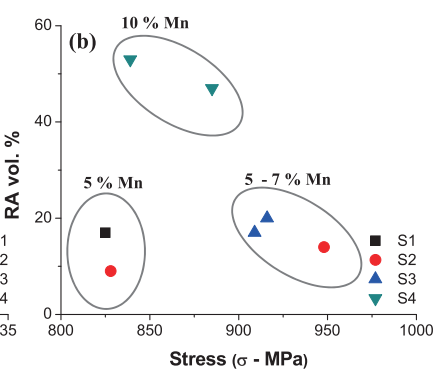

(b)
Fig. 14. The change of (a) strain and (b) stress as a function of retained austenite volume fraction.

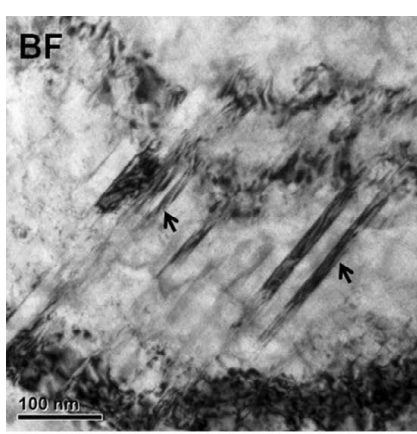

(a)

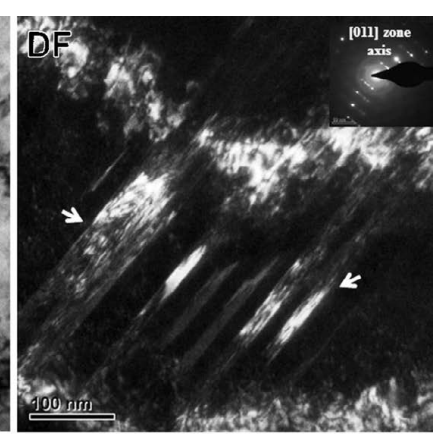

(b)
Fig. 15. Deformation twins in $\mathrm{S} 4$ after $\mathrm{T}_{\mathrm{an}}-1$ annealing and cold rolling; (a) bright field TEM image and (b) weak-beam dark field TEM image with SAED pattern oriented along [011] zone axis (FCC).

tensitic transformation plus twinning in S4 microstructure. At cold rolling of S4 deformation twins are already present in more than $50 \%$ of the grains (Figs. 5 and $\mathbf{1 5}$ as well). Grains without mechanical deformation twins contain a high density of planar dislocation. It is believed that, the increase in the deformation ratio of S4 related with the formation of deformation twins in retained austenite grains. Since twin boundaries act as strong barriers to slip propagation, twinning sustain extra strain hardening effect. ${ }^{17}$ ) Therefore, it 
could be predicted that a gradual formation of deformation twins in retained austenite is necessary to improve cold rollability of medium Mn steels.

In general, $\mathrm{T}_{\mathrm{an}}-1$ has shown better deformation ratio comparing to the $\mathrm{T}_{\mathrm{an}}-2$ annealing process, although, $\mathrm{S} 1, \mathrm{~S} 2$ and $\mathrm{S} 3$ did not reached the desired deformation ratios on both annealing processes. The increase in martensite volume fraction decreased the deformation ratio of these steels due to increasing volume fraction of harder phases. However, total reduction in thickness was increased to 30 to $40 \%$ with several reheating processes in each rolling schedule due to given deformation in each pass (Table 4).

\section{Summary}

In this study, intercritical heat treatments of these medium Mn steels have generated two distinct novel microstructures:

(i) ferrite plus martensite nucleated in austenite microstructure (FMNA structures) (alloys S1, S2 and S3)

(ii) ferrite plus retained austenite duplex structure (FADP steels) (alloy S4)

The FMNA structures are formed with steels having Mn levels between 5 and $7 \mathrm{wt} \%$, by quenching from intercritical temperatures at which the austenite varied between about 25 and $45 \mathrm{vol} \%$. The FADP structure was generated from steel with a $\mathrm{Mn}$ addition of about $10 \mathrm{wt} \%$, intercritically annealed at a temperature at which the austenite was about $50 \mathrm{vol} \%$.

The FMNA structures are heat treatable and could be converted into a tempered martensite (or partitioned structure) - FTMNA, or a TRIP type structure, replacing the martensite with bainite - FBNA structure.

The novelty of structures in this study can be explained by the stability of retained austenite of these alloys. All studies about medium $\mathrm{Mn}$ steels suggested that the general microstructure of $3^{\text {rd }}$ generation AHSS consists of three components: martensite and austenite, which are separate phases, both inside a ferrite matrix..$^{3,8,9,16,18-22)}$ However, the FMNA microstructure consists of martensite nucleated within austenite, and the FADP structure is ferrite plus retained austenite with no other non-equilibrium phase (i.e. martensite or bainite) present.

Generally, the strength and ductility of these steels are affected by several microstructural characteristics, in particular, volume fraction of the retained austenite, its carbon content, plasticity of the metastable phases during deformation, and the ferrite characteristics (grain size). Among these factors, the first three are believed to play the most impor- tant role in controlling the medium Mn steel property. Finally, the results show that the ductility of these medium Mn steels increases with the retained austenite fraction of the microstructure, and the strength increases with martensite volume fraction.

\section{Acknowledgement}

The authors thank to CANMET Materials Technology Laboratory providing the casting and TUBITAK MRC Material Institute for hot rolling facilities. Finally, we would like to thank AUTO - 21 for the financial support for this project.

\section{REFERENCES}

1) B. X. Huang, X. D. Wang, Y. H. Rong, L. Wang and L. Jin: Mater. Sci. Eng. A, 438-440 (2006), No. 11, 306.

2) L. Rémy and A. Pineau: Mater. Sci. Eng., 26 (1976), 123.

3) A. Kumar Srivastava, G. Jha, N. Gope and S. B. Singh: Mater. Charact., 57 (2006), 127.

4) B. C. Cooman, L. Chen, H. S. Kim, Y. Estrin, S. K. Kim and H. Voswinckel: State-of-the-Science of High Manganese Twip Steels for Automotive Applications Micro-structure and Texture in Steels, ed. by A. Haldar, S. Suwas and D. Bhattacharjee, Springer, London, (2009), 165.

5) J. L. Collet, F. Bley, A. Deschamps, H. de Monestrol, J. F. Berar and C. Scott: Solid State Phenom., 130 (2007), 53.

6) O. Bouaziz, S. Allain, C. P. Scott, P. Cugy and D. Barbier: Curr. Opin. Solid St. M., 15 (2011), 141-68.

7) K.-g. Chin, J. Kim and B. C. De Cooman: New Trends and Developments in Automotive System Engineering, ed. by M. Chiaberge, published by InTech, Croatia, (2011).

8) D. K. Matlock and J. G. Speer: Proc. of Int. Conf. on Microstructure and Texture in Steels, ed. by S. Suwas and D. Bhattacharjee, Springer, London, (2009), 185.

9) E. De Moor, J. G. Speer, D. K. Matlock, J.-H. Kwak and S.-B. Lee: Steel Res. Int., 83 (2012), 322.

10) H. Aydin, E. Essadiqi, I.-H. Jung and S. Yue: Mater. Sci. Eng. A, 564 (2013), 501

11) C. W. Bale, E. Bélisle, P. Chartrand, S. A. Decterov, G. Eriksson, K. Hack, I. H. Jung, Y. B. Kang, J. Melançon, A. D. Pelton, C. Robelin and S. Petersen: Calphad, 33 (2009), 295.

12) B. D. Cullity: Elements of X-Ray Diffraction, Addison-Wesley Pub. Co., Reading, MA, (1978).

13) F. Lepera: Metallography, 12 (1979), 263.

14) H. K. Zeytin, C. Kubilay and H. Aydin: Mater. Lett., 62 (2008), 2651.

15) M. McGrath, D. Van Aken and V. Richards: ASM International, OH, USA, (2010), 437.

16) A. Arlazarov, M. Gouné, O. Bouaziz, A. Hazotte, G. Petitgand and P. Barges: Mater. Sci. Eng. A, 542 (2012), 31.

17) S. Vercammen, B. Blanpain, B. C. De Cooman and P. Wollants: Acta Mater., 52 (2004), 2005.

18) H. Aydin, H. K. Zeytin and H. Cimenoglu: Proc. of Epd Congress 2009, ed. by S. M. Howard, TMS, Warrendale, PA, (2009), 191.

19) E. De Moor, D. K. Matlock, J. G. Speer and M. J. Merwin: Scr. Mater., 64 (2011), 185.

20) D. V. Edmonds, K. He, F. C. Rizzo, B. C. De Cooman, D. K. Matlock and J. G. Speer: Mater. Sci. Eng. A, 438-440 (2006), 25.

21) S. Lee, S.-J. Lee and B. C. De Cooman: Scr. Mater., 65 (2011), 225.

22) C. Mirko: Thesis, Master of Science, Tampere University of Technology, (2004). 